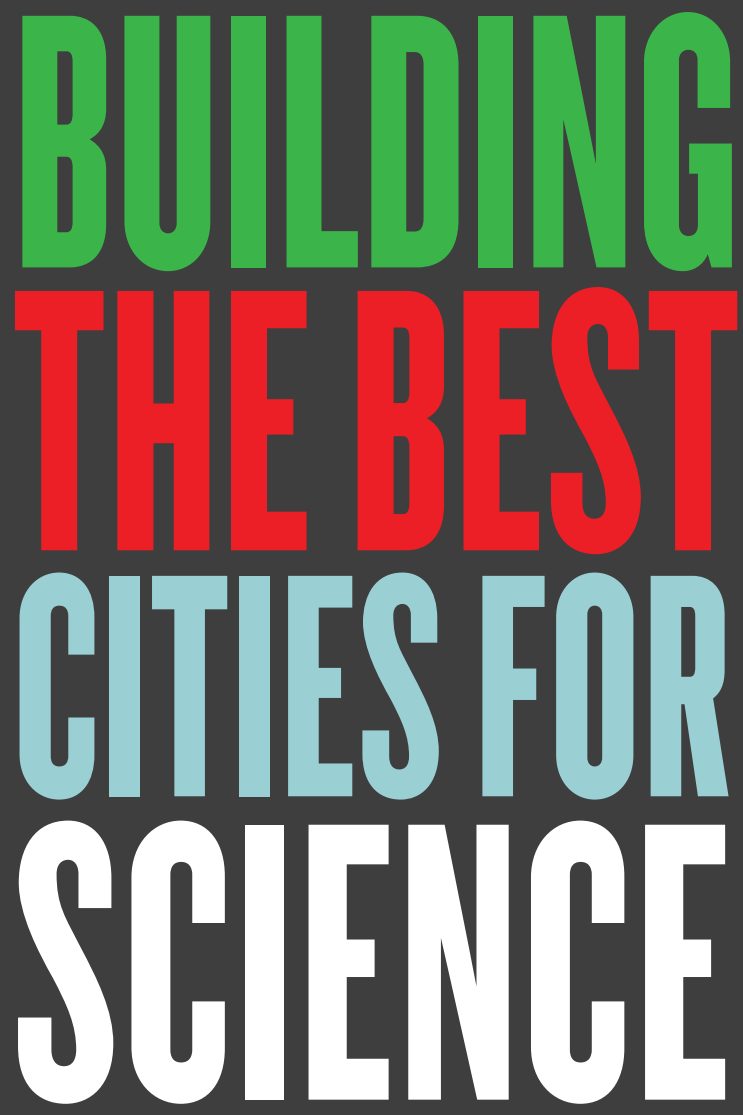

Which urban regions produce the best research - and can their success be replicated?

BY RICHARD VAN NOORDEN

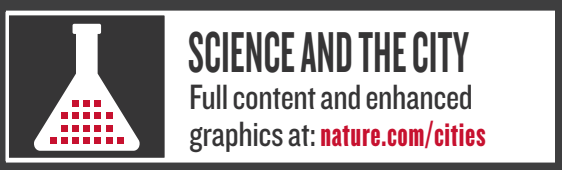

W hen the Øresund bridge connecting Copenhagen, Denmark, with Malmö, Sweden, opened in 2000, both sides had much to gain. Sweden would get a physical connection to the rest of mainland Europe; residents of Copenhagen would have access to cheaper homes close to the city; and economic cooperation would increase. But Christian Matthiessen, a geographer at the University of Copenhagen, saw another benefit - the joining of two burgeoning research areas. "Everyone was talking about the transport of goods and business connections," he says, "and we argued that another benefit would be to establish links between researchers."

Ten years later, those links seem to be strong. The bridge encouraged the establishment of the 'Øresund region', a loose confederation of nine universities, 165,000 students and 12,000 researchers. Co-authorship between Copenhagen and the southernmost province of Sweden has doubled, says Matthiessen. The collaborations have attracted multinational funds from the European Union. And the European Spallation Source, a €1.4-billion (US\$2-billion) neutron facility, is on track to begin construction in Lund, Sweden, in 2013.

The region's promoters claim that it is emerging as a research hub of northern Europe, aided in part by construction of the bridge. For Matthiessen, the bridge also inspired the start of a unique research project - to catalogue the growth and connections of geographical clusters of scientific productivity all over the world.

Most research activities are concentrated around major metropolitan areas. By Matthiessen's count, the top 75 science-producing clusters in the world from 2006 to 2008 generated some $57 \%$ of the research -3.9 million papers. Many argue that a fine-grained analysis might help to identify the factors that drive successful research clusters - indicating rising stars and aiding city planners and policy-makers in building profitable centres elsewhere. In a 2009 paper, Koen Frenken at the University of Utrecht in the Netherlands and his colleagues proposed that studies such as these, which quantitatively map science clusters in physical space, be collected under the general field of 'spatial scientometrics' (K. Frenken, S. Hardeman and J. Hoekman J. Informetrics 3, 222-232; 2009).

Most analyses of success and failure to date have relied on individual case studies. Matthiessen, by contrast, wanted to use data to make global comparative estimates of all cities, in an effort to pick winners and losers. It is not an easy task. Although individual nations and international organizations such as the Organisation for Economic Co-operation and Development do analyse countries for research spending, research quality and numbers of scientists, there are no such data organized at the city level. The fact that geographers don't even agree on how best to define
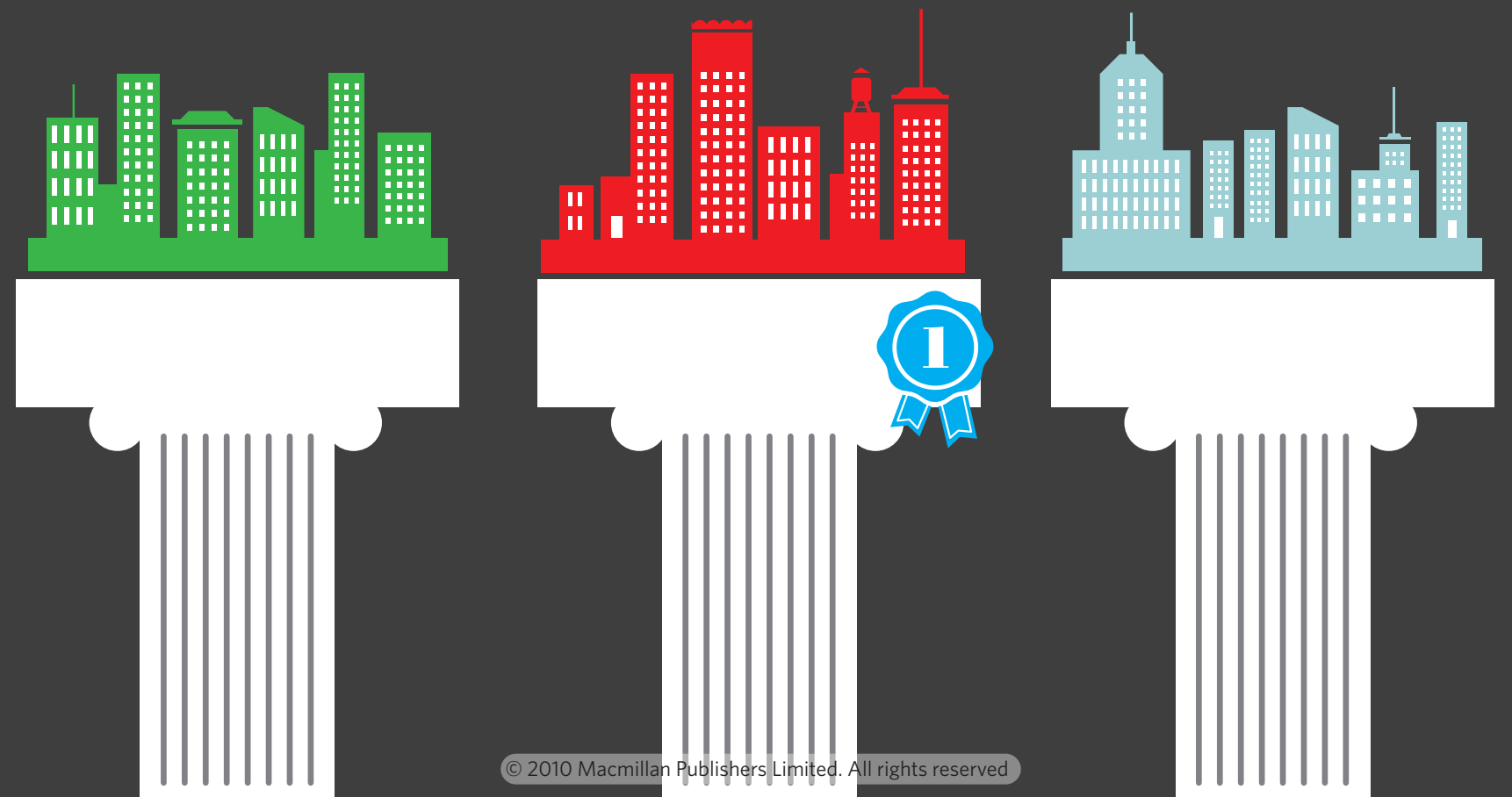
the boundaries of a metropolitan area makes that task doubly difficult. Conflicting definitions of concepts such as 'science cities' and 'innovation clusters' often leave analysts talking past one another. Where Matthiessen wants to look at strength in basic research, most economists and regional planners are concerned with technological innovation: patents and related wealth.

As the global economy continues to flag, bringing such data together is important. "Anthropologists, archaeologists, historians and geographers have argued for many years that cities are the engines of innovation," says José Lobo, a statistician and economist who works on regions and innovation at Arizona State University in Tempe. "But what's difficult is to connect these historical case studies of success with data, so as to create instruments that policy-makers can use."

\section{QUANTITY AND QUALITY}

Matthiessen and his team divide the globe into urban conglomerations on the basis of distances reachable by a 40 -minute commute from a city centre. In this rubric, Oxford and Reading, UK, are one urban region, as are Amsterdam, the Hague, Rotterdam and Utrecht in the Netherlands. By assigning the addresses of research papers' authors to each conurbation, they produced tables of where cities rank in terms of output (C. W. Matthiessen, A. W. Schwarz and S. Find Urban Stud. 47, 1879-1897; 2010).

Topping Matthiessen's list are Tokyo, London, Beijing, the San Francisco Bay Area, Paris and New York (see 'Top cities by publication'). A similar ranking emerges from an analysis provided for Nature by Elsevier, headquartered in Amsterdam, which maintains the Scopus database of journals using the simple method of assigning cities from the address an author provides. Both analyses highlight cities in which scientific output is growing. In particular, Beijing, which churned out $0.76 \%$ of the global output in 1996 , produced $2.74 \%$ in $2008(319,000$ research papers). Other fast-growing areas are Tehran, Istanbul, Seoul, Singapore City and São Paulo.

The results track the economic expansion of Asia and the Middle East and an expanding list of foreign-language journal titles. But they don't necessarily capture the quality of research being published. Elsevier makes that judgement by looking at the average number of citations that a research paper from a city attracts (see 'Top cities by citation'). This paints quite a different picture. Boston and Cambridge, Massachusetts, come out on top - attracting more than twice as many citations per paper as the

\section{TOP CITIES BY PUBLICATION}

An analysis by Christian Matthiessen at the University of Copenhagen and his team looked at the number of publications for broad urban regions. This ranking includes publications from 2006 to 2008.

\begin{tabular}{rc} 
TOKYO-YOKOHAMA & 92,063 \\
LONDON & 90,626 \\
BEIJING & 79,390 \\
SAN FRANCISCO BAY AREA & 71,043 \\
PARIS & 68,430 \\
NEW YORK & 65,587 \\
BOSTON & 63,998 \\
OSAKA-KOBE & 60,256 \\
\hline
\end{tabular}

global average. US cities dominate the quality table, with only Cambridge, UK, breaking into the top 10. Cities with the most improved relative quality in the past decade include Austin, Texas, and Singapore City — which has moved from $15 \%$ below average to $22 \%$ above it. Beijing, however, is below par in the quality stakes: its papers in the five-year period ending 2008 attracted $63 \%$ of the global average-citation rate.

\section{LESSONS FROM BOSTON}

Boston ranks top in several analyses of scientific quality (see 'Top cities by journal', overleaf), and in one sense it is easy to explain why. "Take three or four of the best universities in the world, put them in a city with a seaport, and voilà!" says Lobo. But copying the region's formula is quite another matter. How can one city start to emulate another that attracts the most research funding in the United States and has been built up over centuries?

Having top research universities with mammoth budgets is likely to create a vibrant scientific community - but what can be harder is keeping top scientists in an area long term.

From case studies, Mary Walshok, a sociologist at the University of California, San Diego, picks out three important factors that make cities sticky for scientists. Promise them the freedom to work on their own ideas. Then give them the tools and infrastructure to do so. Public funding is key to achieving these first two aims, but local private corporations and philanthropists who endow new buildings or research chairs also help. "You can see this happening in Austin, and in Seattle," says Walshok.

Walshok's third factor is an attractive lifestyle. Richard Florida, a sociologist and economist at the University of Toronto's Martin Prosperity Institute in Canada, lists scientists among the 'creative class': mobile, talented, creative thinkers that a city must lure in with amenities and smart urban planning. What counts as attractive for this set isn't always obvious. Kevin Stolarick, a statistician also at the Martin Prosperity Institute, suggests that biotech incubators and universities or hospitals should be close enough for a cup of coffee to stay hot when travelling between them. But high culture and hot coffee are not enough to make cities successful in terms of science. A flagging job market will not draw in creative thinkers. Moreover, cities generally held to be the most 'liveable' in surveys - Vancouver and various urban centres in Canada and Australia - are often not associated with outstanding creativity, says Peter Hall, a geographer at University College London. 


\section{TOP CTITES BY JOURNAL}

Luis Bettencourt at Los Alamos National

Laboratory in New Mexico analysed city

addresses appearing in the high-impact

journals Nature, Science and Proceedings of

the National Academy of Sciences. His charts

provide one measure of quality of research.

Boston tops the lists as far back as 1989.

$\rightarrow$ For more data and graphics, see www.nature.com/cities

\section{Nature 2009}

Boston

New York

Tokyo

San Francisco

Los Angeles

Washington DC

San Jose

Chapel Hill-Durham-Raleig

San Diego

Paris
Science 2009

Boston

San Francisco

Washington DC

Tokyo

San Jose

New York

Paris

Los Angeles

San Diego

Chicago

\section{PNAS 2009}

Boston

New York

454

Washington DC

San Francisco

San Diego

Los Angeles

Tokyo

Baltimore

Paris

San Jose
Even with the right ingredients — freedom, funding and lifestyle to attract and keep scientists, there is no guarantee that their work will generate economic wealth. Lobo points out that New Mexico probably has the highest number of physicists per capita in the United States, thanks to the Los Alamos and Sandia national laboratories, but it is hardly an economic powerhouse, as the research doesn't lend itself to commercialization. Boston, on the other hand, has a strong foundation of basic science that has attracted companies and institutes, which in turn has created wealth and attracted more top scientists.

Boston's economic resilience, born of a diverse labour force, is key to this virtuous cycle. Science is merely the latest in a series of economic rebirths - from being the largest city in early colonial America, to a centre for global shipping and sailing in the nineteenth century, to its current position as a biotech hub. Similar tales of success are told for the San Francisco area, with its attractive climate, culture of adventurous investment and laws that favour creative workers. It is illegal in California, for example, to enforce a waiting period before employees move to a competitor's firm, allowing people and ideas to move about freely.

\section{WEALTH SIZED UP}

When it comes to generating wealth from science and technology, a few features seem necessary - but not sufficient. In general, bigger is better. For example, Luis Bettencourt at Los Alamos National Laboratory and Deborah Strumsky at the University of North Carolina, Charlotte, have found that new patents are granted disproportionately to larger urban centres. In this sense, great economic centres such as London, Tokyo and New York are bound to be science strongholds of a sort even though their economic strength comes from other areas, such as financial markets.

Many hold that, for applied research at least, being part of the urban tapestry really works. Cities are natural places for practical research, Bettencourt argues. Still, the question of whether large cities make for better scientists - rather than simply attracting more of them - is fiercely debated.

Smaller cities are not out of the running. Generally, says Lobo, new industries emerge in large cities, but once standardized, they can move to a location with cheaper rents and labour costs. For towns seeking wealth through science, the anchoring presence of a large private research and development laboratory can inject huge benefits. Matthiessen says that the electronics corporation Philips, in Eindhoven, the Netherlands (population 200,000), is an example of a private company working to a local university's advantage by seeking collaborations with research scientists.

But over-reliance on one company or industry can be precarious. Hewlett-Packard's research laboratories outside Corvallis, Oregon, have made the town (population 80,000) one of the United States' most innovative per capita, churning out eight patents per 1,000 population. But if Hewlett-Packard were to fall into decline or the patents run out, Corvallis would probably fall as well, says Lobo.

Given the uncertainties, cities looking for a way to fire up economic engines should not necessarily bet on scientific innovation and technology as a short cut, says Strumsky. "A lot of cities are desperately searching for a way to create jobs, and say: 'Let's invest in biotech research.' You might as well take your money and burn it in a really big pit," she says. If a city has no history or expertise in biotechnology, it must hire its creative inventors from elsewhere, pay them double to move to a biotech backwater, and link their inventions to a local production industry that itself must be made from scratch. Buffalo, New York, is the archetype of a city that made a mistake by investing in biotech research and development labs (see page 912), Strumsky and others have argued. Although unable to retain a skilled labour force, the city is still investing in research.

\section{NATIONAL TRENDS}

Many factors are out of the hands of urban planners and local policymakers, however, and more sophisticated spatial scientometrics studies into why and where scientists cluster geographically could help to explain the influence of these factors. The evolution of a metropolitan region such as Øresund was shaped by national and international policies and economics. National policies, for example, have largely determined the evolution of science cities in France, Spain, Portugal, South Africa and Russia in the past few decades by pushing money, and by extension scientists, into smaller cities in need of a boost.

Michel Grossetti, a sociologist at the University of Toulouse in France, has found that capital cities in these countries lost ground in scientific publications relative to other cities. Henk Moed, a researcher at Elsevier, has in an unpublished analysis shown how from 1996 to 2010, the publication outputs for five major Spanish cities - Valencia, Barcelona, Bilbao, Seville and Zaragoza - have all grown faster than that for the capital Madrid, in parallel with a political trend towards more autonomy for Spanish regions. Grossetti and his team are starting to test how science resources have been concentrated or diffused in cities in every country across the world, from 1978 to 2008. Rather than simply crunching numbers of papers, he wants to take into account population, gross domestic product and institutional shifts. Grossetti hopes that this exercise will start to get to the heart of why science cities rise and fall, and how their evolution is shaped by economic and political factors.

Researchers in the field know they are only starting to illuminate trends. They cannot even agree on whether research is concentrating in particular cities. Matthiessen says it is, but Grossetti says large, rising cities such as Beijing may have skewed the pattern.

How the field may ultimately benefit policy-makers and planners is far from certain. Much development happens by chance. In the Øresund cluster, the universities were swept up in general discussions about transnational integration, and were only later perceived as major catalysts for regional growth, says Bengt Streijffert, retired director of Øresund University. Economic, social and political factors will continue to confound the best-laid plans to optimize a city for science and innovation. And Hall suggests that global data will never displace sound case studies. "Data may be able to show you some interesting outliers - which are not the universities that develop in old cities and flourish there." But, he says, "the number-crunching won't tell you much about the why and the wherefore".

Richard Van Noorden is assistant news editor for Nature. 